\title{
¿REGIONALIZACIÓN DE LA PROVINCIA DE BUENOS AIRES O VUELTA DE LA NUEVA GESTÓN PÚBLICA?
}

\section{REGIONALIZATION OF BUENOS AIRES’ PROVINCE OR THE RETURN OF THE NEW PUBLIC MANAGEMENT}

\begin{abstract}
RicARdo SEbAstián PIANA
Doctor en Ciencia Política -Universidad del Salvador (USAL). Abogado - Universidad Nacional de La Plata (UNLP). Fue docente del curso "Administración Electrónica. La reforma del Estado en la Sociedad de la Información y el

Conocimiento" de la Escuela Complutense Latinoamericana de la Universidad Complutense de Madrid, organizado conjuntamente con la UNLP. Investigador (UNLP) y docente de la materia Derecho Político en la Facultad de Ciencias Jurídicas y Sociales (UNLP), del Seminario de investigación de la UCALP y de la materia Teoría y Derecho Constitucional (USAL). Profesor visitante en Indiana University - School of Law, EE.UU., en el Institut für Informations, Telekommunikations und Medienrecht, Westfaslische Wilhelms - Universität, Münster, Alemania, las Facultades de Derecho de la Universidad de Zaragoza, España, de la Universidad Federal de Santa Catarina, Federal de Rio Grande del Norte, Brasil, Auntónoma de Guadalajara, México y en el Institut de Préparation à l'Administration
\end{abstract}

Générale de la Université d'Auvergne, Francia.

\section{RESUMO}

O Plano de Regionalização da Província de Buenos Aires, nas palavras do atual Governador, implica "numa profunda revisão dos funcionamentos administrativos que nos acompanham desde sempre"; "a estratégia de reengenharia institucional mais importante na história da Província" (Plan de regionalización. Um estado inteligente para a província do futuro (2010, p. 8). Entre os objetivos tão diferentes como harmonizar o desenvolvimento regional, aproximar as instituições da cidadania e reverter a desigualdade social, existem alguns pressupostos acerca do funcionamento do Estado bonaerense que legitimam esta mudança: o conjunto de instituições provinciais não tem alcançado resultados funcionais no desenvolvimento integral da província; a concentração de responsabilidades na administração central prejudica a eficácia de suas ações; uma estrutura institucional distante dos problemas diários; os problemas não podem ser enfrentados eficazmente com as instituições provinciais atuais (fundamentos do projeto de lei). Porém, existem outros pressupostos não explicitados que se deduzem do Estado desejado. Que orientação teórica pode advir desde plano ambicioso?Quais são os pressupostos ideológicos deste projeto de reforma do Estado? Quais são os instrumentos tecnológicos, normativos e organizacionais que se tem pensado como ferramentas de mudança? Estas são apenas algumas das perguntas que orientaram este trabalho.

Palavras-chave: Regionalismo; Buenos Aires; Nova gestão pública.

\section{RESUMEN}

El Plan de Regionalización de la Provincia de Buenos Aires, en palabras del actual Gobernador, implica "una profunda revisión de los funcionamientos administrativos que nos han acompañado desde siempre"; "la estrategia de reingeniería institucional más importante en la historia de la Provincia" (Plan de regionalización. Un estado inteligente para la provincia del futuro, 2010, p. 8). Entre objetivos tan disímiles como armonizar el desarrollo regional, acercar las instituciones a la ciudadanía y revertir la desigualdad social, existen algunos presupuestos acerca del funcionamiento del Estado bonaerense que legitiman este cambio: el conjunto de instituciones provinciales no han resultado funcionales al desarrollo integral de la provincia; la concentración de responsabilidades en la administración central resta eficacia a su accionar; una estructura institucional alejada de las problemáticas cotidianas; los problemas no pueden enfrentarse eficazmente mediante la actual institucionalidad provincial (fundamentos del proyecto de Ley). Pero existen otros presupuestos no explicitados que se deducen del Estado deseado. ¿Qué orientación teórica puede advertirse en este ambicioso Plan? ¿Cuáles son los presupuestos ideológicos de este proyecto de reforma del Estado? ¿Cuáles son los instrumentos tecnológicos, normativos y organizacionales que se han pensado como herramientas del cambio? Estas son algunas de las preguntas que orientarán este trabajo.

Palabras-clave: Regionalismo; Buenos Aires; Nueva Gestión Pública. 


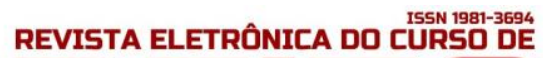

\section{SUMÁRIO}

INTRODUÇAO; 1 EL REGIONALISMO; 2 LA REGIÓN EM EL DERECHO PÚBLICO ARGENTINO; 3 EL PROYECTO DE LEY DE MARCO PARA LA REGIONALIZACIÓN DE LA PROVÍNCIA DE BUENOS AIRES; 3.1 Breve contexto; 3.2 El proyecto de ley Marco para la Regionalización de la Provincia de Buenos Aires; 3.3 Las líneas ideológicas del proyecto. CONCLUSÃO; REFERÊNCIAS.

\section{EL REGIONALISMO}

Entre los grandes actores de la política internacional, el Estado se nos aparece como el que presenta mayores dificultades: los nuevos protagonistas son, por una parte, los mercados y, por otra, las organizaciones transnacionales en un heterogéneo recorrido que va desde las opiniones públicas, los movimientos por la paz, los ecologistas, las organizaciones terroristas, la macrocriminalidad organizada, etc. (Piana, 2012).

¿Las causas? Por un lado, la desterritorialización de la riqueza y la consecuente pérdida de control del Estado sobre la economía - de la soberanía monetaria y crediticia al control del factor trabajo, pasando por el drenaje fiscal- parece ser una de las causas ${ }^{1}$. La separación del mando político y el económico constituye el estado de tensión característico de la situación presente de la democracia capitalista. Por otro lado, la imposibilidad de hacer frente a desafíos trasnacionales como los que tienen que ver con los terremotos en los mercados de acciones, las presiones migratorias o las emergencias ecológicas constituyen fenómenos irreversibles en el mundo contemporáneo que dan muestras de la imposibilidad de resolver este tipo de fenómenos en el marco de las fronteras políticas nacionales (Portinaro, 2003).

El regionalismo moderno, entre la globalización y los Estados nacionales, parece ser un punto de encuentro de lo "glocal".

La región suele identificarse por poseer un territorio, integrador de otras unidades políticas, y elementos geográficos, sociológicos, históricos, religiosos, culturales, económicos o jurídicos que la dotan de cierta homogeneidad. Pero como ha señalado Ferrando Badía (1976) la región es independiente de las estructuras políticas, que podrán reconocerla o no sin que por

\footnotetext{
${ }^{1}$ Crisis económicas locales como las de EE.UU. en 2007 y 2009, y la actual crisis europea con catastróficos efectos sobre el empleo y los "gastos" sociales, no serán nunca más locales; serán globales desde que el capital no reconoce fronteras ( $y$ ha encontrado Estados suficientemente ingenuos como para creerlo)
} 


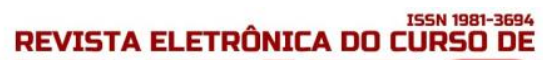

ello disminuya su importancia; es decir, el elemento político que la crea o reconoce o incluso las dota de personalidad jurídica propia no es esencial².

Ha señalado Dalla Vía (2000) entre las razones que impulsan el desarrollo del regionalismo, la histórica, entendiendo no solo la existencia anterior de comunidades o pueblos con autonomía o independencia, sino también la cristalización de una cultura o identidad propia a través del tiempo. Para otros autores, la razón de ser de los procesos de regionalización es viabilizar un nivel de crecimiento económico más estable y fortalecer la posición económicapolítica de los países involucrados en el escenario internacional; la formación de bloques económicos puede entenderse como la transición hacia el establecimiento de una economía con mercado mundial (Piaggi, 1999).

Cuando no surgen de la formalización de una situación natural pre-existente o cuando ésta no ha sido lo suficientemente fuerte como para que las mismas se creen por sí solas, Bianchi y Seville Salas (1996) han señalado las siguientes motivaciones para la creación de regiones: a) disminuir las desigualdades existentes entre las diferentes unidades políticas que la integran; b) combatir el estancamiento económico; c) establecer un mayor grado de comunicación entre las regiones; d) mayor apoyo al desarrollo de las áreas productivas en detrimento de las que se consideran deficitarias; e) favorecimiento de las economías de escala; f) mejor aprovechamiento de los recursos naturales; g) aumento de la inversión en vistas de un mayor número de consumidores; h) obtención de menores costos, y por ende mayor competitividad de los productos regionales; etcétera.

Pero lo cierto es que la integración regional, como fenómeno que aparece en Europa tras la segunda guerra mundial, superó el marco teórico de los estudios de las Relaciones Internacionales (Conf. Mellado, 2005).

Entendido como un proceso similar al State Building que se da entre las autoridades nacionales y subnacionales en un Estado Federal donde el eje se da en el éxito de la conformación de un poder central, pasando por concepciones funcionalistas, para las que el regionalismo atiende la incapacidad de los Estados nacionales para resolver los problemas técnicos y donde una integración sectorial iniciada en lo económico puede alcanzar

\footnotetext{
${ }^{2}$ Ya lo decía Joaquín Víctor González (1913:784) "En nuestra organización nacional existen dos factores: La provincia y la región. Todo organismo federativo consta de estos dos órdenes de elementos: La organización política, que es absolutamente voluntaria, convencional, constitutiva y ordinaria; y la región o distribución regional que obedece a causas de orden no voluntario ni convencional, sino que tienen su principal fuente en la vida material, en caracteres étnicos, territoriales y sociales de la misma nacionalidad".
} 


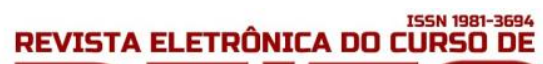

posteriormente la integración política, hasta llegar a la teorías neofuncionalistas donde el éxito político depende de las demandas, expectativas y lealtades de los actores políticos afectados por el proceso, el fenómeno de la integración regional ha sido estudiado especialmente centrado en el caso de la hoy Unión Europea. Obviamente en estas explicaciones no faltan las visiones economicistas que entienden la integración regional como una supresión al movimiento de mercancías coordinadas por el mercado o por los Estados, proceso que puede llevar o no a la integración política. Tampoco faltan explicaciones del realismo, neorrealismo, constructivismo, etc. $^{3}$

Desde nuestra región el concepto de Regionalismo Sudamericano ha ido creciendo de la mano de los órganos e instrumentos internacionales que han ido conformando un bloque regional cada vez más complejo y heterogéneo (ALALC, ALADI, MERCOSUR, CAN, UNASUR, etc.). En efecto, el concepto de regionalismo abierto, en nuestro contexto, reconoce su fuente en el documento de la CEPAL de 1994 que lo entiende como un proceso de creciente interdependencia económica, basado tanto por acuerdos de integración como en políticas de apertura y desreglamentación para una economía internacional más abierta y trasparente. Pero como hemos destacado en otros trabajos (Piana, 2009), el estado intergubernamental del bloque del MERCOSUR, sin delegación de competencia, con un fuerte eje en las reuniones presidenciales, ha marcado una realidad distinta a las visiones teóricas locales.

En verdad, un fenómeno complejo como el de la integración regional, con múltiples experiencias y realidades, no admite reduccionismos teóricos y debe ser abordado desde la economía, la política, lo jurídico y lo social.

Y si bien es cierto que el estudio del regionalismo se ha puesto en ese nivel, entre lo global y lo estatal-nacional, no hay impedimento para trasladar esa mirada a una micro escala y analizarlo como posibilidad de articulación entre lo estatal-nacional y las provincias o aún, dentro de una misma provincia como micro-regiones mediadoras entre la provincia y los municipios.

\footnotetext{
${ }^{3}$ Ver la extensa descripción de las diversas teorías que hace Mellado (2005) en el trabajo ya citado en el cuerpo del artículo.
} 


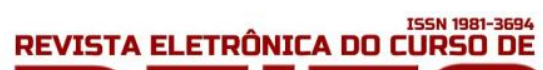

\section{LA REGIÓN EM EL DERECHO PÚBLICO ARGENTINO}

El regionalismo nacional se enmarca en el ámbito del derecho intrafederal, pero como aclaran Domingo y Moscariello (2007), no quiere decir sin más y necesariamente federal porque, como veremos, la creación de regiones es una potestad de las provincias.

El art. 124 de la Constitución Nacional reformada en 1994 señala que "Las provincias podrán crear regiones para el desarrollo económico y social y establecer órganos con facultades para el cumplimiento de sus fines..." y el siguiente, anterior 107, que "Las provincias pueden celebrar tratados parciales para fines de administración de justicia, de intereses económicos y trabajos de utilidad común, con conocimiento del Congreso Federal...".

Pero los alcances de este regionalismo aún son discutidos. Pensado como mecanismo para fortalecer nuestro federalismo atenuado, el texto constitucional aparece ser limitativo en cuanto a los fines de la creación de las regiones: el desarrollo económico y social de las provincias que la integran.

Sin embargo, esta limitación debe ser leída en el marco del actual art. 125 Constitución Nacional. Este último artículo ha dado base a acuerdos de todo tipo, desde la realización de obras de infraestructura, la creación de entes interjurisdiccionales como el C.F.I., incluso de carácter comercial, como el Mercado Central de Buenos Aires.

¿Pero cuál es la naturaleza jurídica de estas regiones? La interpretación debe jugar, además de los artículos ya citados, con el texto del art. 121 de la Constitución Nacional que establece que "Las Provincias conservan todo el poder no delegado por esta Constitución al Gobierno federal, y el que expresamente se hayan reservado por pactos especiales al momento de su incorporación" y que se dan sus propias instituciones y organizan sus poderes sin intervención del gobierno federal, dictan sus leyes de procedimiento y eligen sus jueces dentro de las exigencias de los arts. 5 y 75 inc. 12 de la Constitución Nacional.

La tesis más fuerte de la doctrina nacional, inicialmente señalada por Bidart Campos (1995) sostiene que las regiones no tienen poder político ni pueden tener competencias propias independientes de las provincias que las crean. Y aclara que, por faltar el nivel de decisión política, las relaciones entre provincias regionalizadas habrán de ser relaciones intergubernamentales, que no podrán producir desmembramientos en la autonomía política de las provincias. 
Para Sabsay y Onaindia (1994) la atribución para crear regiones se restringe al desarrollo económico y social y la potestad para crear órganos regionales se encuentra limitada al cumplimiento de los fines económicos y sociales de la región. En esta línea Klass (2004) señala que este regionalismo significa una forma descentralizada de política de base territorial, sin que ello represente intercalar una nueva estructura política en la organización tradicional de nuestro régimen, en el que se mantiene la dualidad distributiva del poder entre el Estado federal y las provincias.

Más recientemente, afirma Sabsay (2013) que la región para el constituyente es un modo de descentralización administrativa del poder en el territorio. Según esta línea interpretativa, el regionalismo interprovincial busca la unión de esfuerzos para racionalizar gastos y erogaciones, teniendo las regiones una limitada autarquía para la concreción de las metas económicas y sociales propuestas (Conf. Rosatti, 1994; Badeni, 1994). Se añade, además que las regiones no tienen capacidad jurídica plena ni aparecen como personas jurídicas públicas entre las enumeradas por el artículo 33 del Código Civil (ver Domingo y Moscariello, 2007) ${ }^{4}$.

Otra línea interpreta que las provincias podrían delegar competencias en órganos regionales, siempre y cuando no se trate de potestades prohibidas por la Constitución y siempre que tal delegación no implique crear un nuevo Estado con competencias políticas que interfieran en el ejercicio de competencias otorgadas por la constitución al gobierno central. Según Gordillo (1998:26) " No nos parece que esas finalidades deban interpretarse restrictivamente: una unidad regional con justicia propia, fines económicos y sociales propios, es también una región con personalidad jurídica propia y entidad política propia". Según esta línea no existe limitación para la creación de una persona de derecho público a la cual imputar los actos de esa organización sin que ello suponga crear un nuevo Estado intermedio entre la Nación y las Provincias (ver Domingo y Moscariello, 2007).

Finalmente otros autores entienden que la naturaleza y competencias regiones dependerá de las respectivas delegaciones que acuerden efectuar las provincias que las compongan en cabeza de los órganos que las dirijan ya que del silencio constitucional no debe desprenderse una prohibición al respecto (ver Bianchi y Seville Salas, 1996) ${ }^{5}$. Es por ello que

\footnotetext{
${ }^{4}$ Sin embargo, estos autores propugnan la necesidad de dotar a las regiones de personalidad jurídica mediante una ley nacional que modifique el código civil y se las reconozca expresamente.

${ }^{5}$ Estos mismos autores señalan que las provincias, en ejercicio del art. 124 de la Constitución Nacional podrían decidir someterse, a través de un tratado interprovincial del art. 125 de la Constitución Nacional, a la legislación que dictaran los órganos creados al efecto si no existiera algún impedimento en las
} 
algunas regiones tendrán competencias para tomar decisiones por sí solas y otras solamente podrán ejecutar las que las provincias que las compongan adopten a través de tratados que al efecto dicten.

En cuanto a la facultad de su creación, la mayoría de la doctrina afirma que es una facultad exclusiva y excluyente de las provincias aunque nada impediría que sean creadas en forma concurrente con la Nación sobre la base del art. 75, inc. 19 de la Constitución Nacional, ya sea por acuerdos interjurisdiccionales o por adhesión voluntaria de las provincias a una leyconvenio del Congreso de la Nación (conf. Bidart Campos, 1995) ${ }^{6}$. Así, Sabsay (2013) señala que, sin perjuicio de que la creación sea una competencia exclusiva de las provincias, la creación de regiones debería coordinarse o concertarse, para que la regionalización realizada en virtud del art. 124 de la Constitución Nacional, guarde relación con las políticas federales diferenciadas del art. 75, inc. 19 de la Constitución Nacional ${ }^{7}$.

Más allá de los límites interpretativos de esta base constitucional, lo cierto es que nuestro federalismo encuentra un desarrollo limitado en detrimento de las provincias por una tenencia natural e histórica centralista. ${ }^{8}$

Ya antes de la modificación de nuestra Constitución Nacional, las regiones del NOA y la Patagonia ya habían marcado un precedente importante en este movimiento y, con posterioridad, las provincias argentinas han demostrado su interés en utilizar estos mecanismos:

respectivas constituciones provinciales. Sin embargo, reconocen que las regiones están por debajo de las provincias y no pueden ser entes superiores a ellas.

${ }^{6}$ Una variante es la opinión de Quiroga Lavié (1996) al afirmar que es el Congreso quien debe dictar una ley de bases generales para la regionalización y, dentro de esta legislación de bases, las provincias podrán determinar sus prioridades regionales y sus acuerdos para llevarlos a cabo.

${ }^{7}$ Obviamente, aquí no se cierra el debate y hay muchas otras cuestiones de interpretación constitucional. A modo de ejemplo, transcribimos a Hernández (1997:97) quien vislumbra en sus afirmaciones la riqueza aún inexplorada de este instituto: "a) Además de las provincias, pueden intervenir los otros órdenes gubernamentales: el federal, la ciudad de Buenos Aires y los municipios... b) Una provincia puede formar parte de más de una región, si así lo requiere su desarrollo. c) No debe existir necesariamente un solo mapa regional en la Argentina. d) La descentralización del gobierno federal no debe unirse en forma imprescindible con la regionalización de las provincias... f) La regionalización del país para la integración y el desarrollo económico y social, también supone una interrelación con la integración supranacional y la provincial, que exigirá la promoción de las relaciones intermunicipales. g) La regionalización, como instrumento del proyecto federal, requerirá de una concertación interjurisdiccional con eficaz gestión técnica y alta calidad en la dirección política."

${ }^{8}$ Escapa a los objetivos de este trabajo pero no podemos dejar de mencionar que las autonomías provinciales se han visto limitadas, tanto por factores económicos como por la uniformidad de legislación, la enorme gravitación de los partidos nacionales y la natural tendencia del ejecutivo nacional de llevar adelante políticas unificadas. Pero también la gran disparidad geográfica, de recursos y demográfica conspiran contra un federalismo equilibrado. 
- El junio de 1996, Chubut, La Pampa, Neuquén, Río Negro9 , Santa Cruz y Tierra del Fuego ${ }^{10}$ suscribieron el Tratado fundacional de la Región Patagónica a fin de proveer el desarrollo humano y al progreso económico y social ${ }^{11}$.

- En agosto de 1998 las Provincias de Córdoba y de Santa Fe suscribieron un Tratado de Integración Regional al que se unió mediante un Acta de Integración la Provincia de Entre Ríos $^{12}$.

- En 1999, a partir de la suscripción del Tratado parcial interprovincial, se crea la Región Norte Grande Argentino (NOA y NEA) integrada por las provincias de Catamarca, Corrientes, Chaco, Formosa, Jujuy, Misiones, Tucumán, Salta y Santiago del Estero. En 2012, La Rioja se reincorpora al proceso de integración de las provincias del NOA y por ende del Norte Grande ${ }^{13}$.

Sin embargo, el desarrollo institucional de estas regiones ha sido lento ${ }^{14}$. $\mathrm{Y}$ el apoyo de las autoridades nacionales para el impulso de estas regiones tampoco ha sido fructífero ${ }^{15}$.

${ }^{9}$ El art. 10 de la Constitución de la provincia de Río Negro dice: "La provincia de Río Negro declara su pertenencia a la Región Patagónica...".

${ }^{10}$ La otra expresa adhesión a los postulados regionalistas lo tiene la Constitución de la Provincia de Tierra del Fuego que en el preámbulo declara a "La Provincia (...) perteneciente a la región patagónica y coordina su política, planes y gestiones con las provincias de la región y el Estado Nacional".

11 Poco después suscriben el Estatuto de la Región Patagónica donde se crean como Órganos de Gobierno de la Región, a la Asamblea de Gobernadores y el Parlamento Patagónico, como Órgano Ejecutivo la Comisión Administrativa y como Órgano de Asesoramiento y Consulta el Foro de Superiores Tribunales de Justicia de la Patagonia

${ }_{12}$ Los órganos Regionales son la Junta de Gobernadores, como órgano Superior de la Región, un Comité Ejecutivo, una Secretaría Administrativa y Comisión Parlamentaria Conjunta.

${ }^{13}$ El Consejo Regional del Norte Grande (CRNG) es el máximo ente regional, integrado por la Asamblea de Gobernadores (AG), la Junta Ejecutiva (JE) y el Comité Coordinador constituido por un representante del NOA y otro del NEA, ambos, además, miembros de la Junta Ejecutiva. En la actualidad funcionan como tal, la Asamblea de Gobernadores, el Comité Coordinador integrado por el representante de Salta en representación del NOA y un representante del Chaco, en representación del NEA. Finalmente, la Comisión Ejecutiva Interministerial de Integración Regional (CEIIR), que coordina -por mandato del Tratado- el proceso de integración a partir de las directivas de los órganos superiores antes mencionados. Este año, se ha presentado al Congreso un proyecto de ley para el desarrollo del NEA-NOA. Ver http:/ / www.regionnortegrande.com.ar/. Fecha de acceso 17/09/2014.

${ }^{14}$ En el caso de la Región Centro, recién se reglamenta el funcionamiento de la Junta de Gobernadores y del Comité Ejecutivo mediante la firma del Protocolo de Córdoba en 2004. En el caso de la Región del Norte Grande Argentino también en 2004, en el Acta de Resistencia, se dio a conocer el Estatuto para el funcionamiento del Consejo Regional del Norte Grande.

${ }^{15}$ Sólo podemos destacar el proyecto de ley de regionalización para el desarrollo económico y social de 1996 (Expediente 906/96 del H. Senado) donde se establecía la creación de la región como unidad de organización territorial y de administración económica y social, sobre la base de la integración para el 


\section{EL PROYECTO DE LEY MARCO PARA LA REGIONALIZACIÓN DE LA PROVINCIA DE BUENOS AIRES}

\subsection{Breve contexto}

Ajena al marco de integración interprovincial que se ha dado entre las provincias argentinas se encuentra la provincia de Buenos Aires que ha intentado recientemente diseñar su proceso de regionalización hacia dentro de su territorio.

La Provincia de Buenos Aires es el estado local de mayor importancia de la República Argentina en cuanto a su población, producción y superficie, siendo un caso representativo de las propias diferencias que existen en todo el país: tiene una superficie de $307.571 \mathrm{Km}^{2}$, lo cual representa un $8,26 \%$ respecto del total del país pero representando geográficamente menos del $10 \%$ del territorio nacional, su población, totaliza 15.594.428 de habitantes según datos del censo 2010, esto es, casi un $40 \%$ del total nacional ${ }^{16}$.

Decíamos que la Provincia es representativa de las diferencias que existen en todo el país, pues en ella también puede verse reproducida la desigual distribución de la población. En el conurbano, que ocupa una superficie de $3.630 \mathrm{~km}^{2}$, esto es, un porcentaje de $1,2 \%$ respecto de su superficie total, habita el 63,55 \% de su población (9.910.282 hab.). Por ello, al igual que la Argentina, de la Provincia de Buenos Aires puede decirse que es un Estado macrocefálico.

Ha señalado Ollier (2011) una peculiar imbricación, con referencia al caso de la Provincia de Buenos Aires, de las instancias nacional y provincial, tanto por el rol preponderante de esta Provincia en la política nacional como del impacto decisivo de la política nacional en su territorio pero también por un natural proceso de cooperación entre ambas jurisdicciones. En efecto, su carácter des/estabilizador sobre la nación se evidencia no sólo en los resultados

desarrollo de una provincia o del conjunto de provincias que la componen. Pero en ese mismo proyecto, luego de aclarar las posibles competencias conjuntas determinaba que en ningún caso la regionalización podría afectar la autonomía de las provincias y el pleno ejercicio de sus competencias políticas (art. $8^{\circ}$ ). Autores como Barrera Buteler (1996) y Klass (2004) justifican este tipo de leyes de concurrencia entre Nación y provincias para cumplir con la competencia del Congreso en cuanto a proveer lo conducente al adelanto y bienestar de todas las provincias (Const. Nacional, art. 75 inc. 18) y al crecimiento armónico de la Nación (Const. Nacional, art. 75 inc. 19).

16 Ello representa un pequeño aumento en el porcentaje atento a que en 2001 representaba el 38,13\% de la población total de Argentina para pasar a 38,90\% en 2011. 
electorales provinciales, sino más bien, últimamente, por la búsqueda del gobierno nacional en “decidir" los candidatos a los cargos provinciales ${ }^{17}$.

La hegemonía ininterrumpida del Partido Justicialista en la Provincia de Buenos Aires desde el año 1987 hasta la actualidad, expresa un electorado significativamente fiel, en buena medida cautivo. En esta estructura territorial, los actores políticos de peso son pocos (Camou, 2005). En verdad, si se analiza todo el período desde el retorno a la democracia (1983-2014), éste describe la declinación del Partido radical y la creciente hegemonía del peronismo en los cargos provinciales, por un lado, y por otro, la irrupción local de una tendencia global: el debilitamiento del rol del partido tradicional y el crecimiento personalista de las figuras extrapartidarias.

Luego de la gobernación radical de Alejandro Armendáriz, el Partido Justicialista ocupó el Poder Ejecutivo cuando, en 1987, Antonio Cafiero ganó las elecciones con el 46\% de los votos superando a la Unión Cívica Radical en siete puntos porcentuales. En 1991, Eduardo Duhalde asumió la gobernación con el $47,7 \%$ de los votos y fue reelecto, luego de la reforma de la Constitución Provincial en 1994 en 1995 con el 56,7\% de los sufragios. En 1999, pese a haber perdido las elecciones de diputados de 1997, volvió a ganar el Partido Justicialista la gobernación con el 48,3\% de los votos con Carlos Ruckauf contra el 41,4\% para la Alianza (UCR y FREPASO) $)^{18}$.

El gobernador Solá validó su mandato en 2003 con la fórmula Solá-Giannettasio ${ }^{19}$. Y si bien el oficialismo en las Cámaras obtuvo un fuerte triunfo ${ }^{20}$ el gobierno de Solá no gozó de los beneficios de contar con mayoría legislativa: la disciplina partidaria se encontró en crisis y existieron conflictos en la relación entre el Poder Ejecutivo y el Poder Legislativo como consecuencia de la lucha por el liderazgo entre Duhalde y Kirchner ${ }^{21}$. Este hecho resulta

\footnotetext{
17 Se advierte en las últimas décadas la "nacionalización" de los discursos, políticas y acciones de la Provincia. Por último, aunque menos evidente, ambas Jurisdicciones entablan distintos procesos colaborativos que reconocen esta tensión relacional.

18 Debe destacarse que la adhesión de Ruckauf a la postulación de Cavallo a la presidencia, le "sumó" al primero de casi $8,8 \%$.

19 Duhalde, entonces en ejercicio de la presidencia, se involucró de manera personal y directa en la continuidad de Solá (conf. Rodríguez y Rodríguez Blanco, 2004).

20 En Diputados obtuvo 28 de los 46 cargos en disputa y en Senadores 19 de los 23.

${ }^{21}$ A fines de 2004 la división en el bloque de legisladores oficialistas bonaerenses, dejando en minoría a los partidarios del Gobernador F. Solá, aliado del Presidente, y la negativa a incluir en la aprobación del presupuesto provincial la delegación de poderes en el ejecutivo tal como sucedía en el ámbito nacional, dieron la tónica de un conflicto creciente que preanunciaba la ruptura que se produciría para las elecciones legislativas de 2005. Luego de que esa ruptura se produjera, el oficialismo se encontró en minoría en varias oportunidades, al menos durante el segundo semestre de 2005 y hasta que se produjo la
} 
trascendental para explicar la “introspección” que se dio en el período en materia de reforma de la Administración Pública y del Estado: con excepción de las leyes de emergencia ${ }^{22}$, las reformas se dieron hacia dentro del Poder Ejecutivo ${ }^{23}$; fueron reformas de la Administración Pública, sin pretender afectar los fines del Estado (que hubieran requerido de un aval legislativo) ${ }^{24}$.

Distinto ha sido el proceso de llegada al ejecutivo bonaerense de Daniel Scioli y el contexto bajo el cual ha gobernado hasta la fecha. Pese al ostracismo al que había sido conminado en su cargo de Vicepresidente de la Nación durante el gobierno de Néstor Kirchner, supo recomponer esa relación y ser nominado como candidato a Gobernador, contando desde entonces con fuerte apoyo popular y en las urnas ${ }^{25}$ aunque con un relativo poder territorial. La fórmula Scioli-Balestrini se impuso con el apoyo del 48,24 \% de los votantes y renovó su cargo en

renovación parlamentaria (Cheresky, 2006:48). La existencia de estas divisiones internas que se plasman sobre todo en la Cámara de Diputados generaron una relación entre el Poder Ejecutivo y el Poder Legislativo de delicados equilibrios, que se puso de manifiesto en la necesidad de realizar permanentes negociaciones en el ámbito de la labor legislativa y en las modificaciones realizadas a las leyes antes de ser aprobadas.

22 Ley $\mathrm{N}^{\circ} 12.727$, que fuera sancionada durante el gobierno de Ruckauf, luego modificada y ampliada por sucesivas leyes: Leyes $N^{\circ} 12.774,12.775,12.789,12.836$ y $12.845,13.242$ y 13.850 .

${ }^{23}$ Entre las normas de nivel de gobernador en lo que hace a la temática de reforma de la Administración y del Estado podemos destacar los siguientes normas: Decreto № 2905/02 Banco de Proyecto Exitosos; Decreto No 47/03 Programa "Carta compromiso con el Ciudadano"; Decreto No 540/03 Agentes de Modernización; Decreto $N^{\circ}$ 184/03 Guía Única de Trámites; Decreto $N^{\circ}$ 1.204/03 Red Única Provincial de Comunicación de Datos; Decreto N 1.329/04 Programa de Voto Electrónico; Decreto №1867/04 Banco de Proyectos de Innovación de la Gestión Pública; Decreto № 1208/05 que aprueba el Programa de Formación para la Alta Dirección en el Estado; Decreto $N^{\circ}$ 1.322/05 Régimen para la formulación, financiación, presentación, tramitación y aprobación de estructuras; Decreto $\mathrm{N}^{\circ}$ 1.676/05 que aprueba el pliego único de bases y condiciones generales para la contratación de bienes y servicios de la Prov.de Bs. As. y de los pliegos tipo de bases y condiciones particulares por tipo de demanda; Decreto $N^{\circ} 2.442 / 05$ Régimen sobre el Uso Responsable de Elementos Informáticos; Decreto N².704/05 Sistema de Información Normativa de la Provincia de Buenos Aires (SINBA); Decreto N ${ }^{\circ} 300 / 06$ (modif. por Decreto $N^{\circ} 2200 / 06$ ) Guía de la comunicación escrita en la administración pública; Decreto № 196/06 Sistema Integrado de Emisión y Pagos no Impositivos (SIEP); Decreto N ${ }^{\circ} 1.859 / 07$ Sistema de Conjuntos Mínimos de Datos (CMD). Para un análisis en profundidad del proceso de reforma provincial del período puede verse Pagani et. al (2012) y Piana (2012b).

${ }^{24}$ Randazzo impulsó un proyecto de ley que aprobaba un Plan Rector de Modernización que modificaba estructuralmente el modelo del Estado bonaerense, pero que no contó con acompañamiento en las cámaras. Véase Randazzo (2004).

${ }^{25}$ La excepción fue la dura derrota legislativa en territorio bonaerense del Frente para la Victoria en 2009 (más por su impacto político que por los guarismos), donde asumió carácter de candidato a legislador "testimonial” junto a Néstor Kirchner. En Piana y Baeza (2013) analizamos la estrategia de marketing político de De Narváez en las elecciones de 2009. 


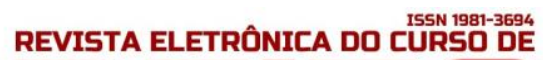

2011, con Gabriel Mariotto como compañero de fórmula, con el 55,06\% de los votos con un amplio margen respecto a la segunda fórmula más votada ${ }^{26}$.

Pese a los ambages de ruptura, Scioli se ha mantenido encolumnado detrás del proyecto político de la presidenta Cristina Fernández de Kirchner. Aún con críticas de los sectores más kircheneristas, ha contado con acompañamiento legislativo ${ }^{27}$. En materia de reforma del Estado y de la Administración, antes de asumir contó con el apoyo de las Cámaras para aprobar una nueva Ley de Ministerios ${ }^{28}$ y Ley de Administración Financiera ${ }^{29}$, y a dos años una nueva ley de contrataciones $^{30}$, sustituyendo estas dos últimas a la vetusta pero tradicional Ley de Contabilidad de la Provincia del año $1971^{31}$. A grades rasgos, analizado en contraposición con el período anterior, y aún reconociendo que ha habido mucha modificación normativa, éste período puede caracterizarse como de implementación de muchas de las políticas de reforma administrativas ya sancionadas en la gestión anterior ${ }^{32}$.

Este contexto, el de introspección con reforma administrativas primero y de ejecución de estas reformas en segundo lugar, dificultaría analizar los paradigmas de las reformas. En efecto, en la gestión de los procesos administrativos, los criterios de eficiencia y eficacia suelen identificarse como los principios claves para instrumentar las reformas meramente administrativas en torno a ciertos fines del Estado, definidos en un contexto político superior. La tecnoburocracia apela a estos postulados para legitimar su accionar. Pero detrás del velo hay política o como mejor ha dicho Aguilar Villanueva (2006), bajo toda teoría de la gestión pública ha de encontrarse siempre una cierta visión del Estado que responda por ella. En ese marco debemos analizar el proyecto de ley marco para la regionalización de la provincia de Buenos Aires en cuanto implicaría una "una profunda revisión de los funcionamientos administrativos que nos han acompañado desde siempre" (Plan de Regionalización... 2011:8) y “la estrategia de

26 http://www.elecciones2011.gob.ar/paginas/paginas/dat02/DG002999A.htm. Fecha de consulta: 29/05/14.

${ }^{27}$ Este proceso de ralentizó con la asunción de Mariotto en el Senado, pero no por ello se detuvo.

${ }^{28}$ Promulgada antes de la asunción, el 27/11/07

${ }^{29}$ Ley $N^{\circ} 13767$, promulgada el día de su asunción.

30 Ley $N^{\circ} 13981$, promulgada el 8/4/09. Sin embargo, no ha entrado en vigencia por la falta de reglamentación.

31 Decreto-Ley № 7.764/71.

${ }^{32}$ Puede verse en la nota 23 un listado de los proyectos que durante la actual gestión no se modificaron. El único caso es el Decreto que creó la figura de los Agente de Modernización que tenía un plazo de vigencia. Actualmente, se encuentra vigente el Programa de Especialización en Gestión Pública, creado mediante Decreto № 2133 del año 2009 que actualmente cuenta con 23 cargos de Expertos en Gestión Pública (conf. Decreto No 209/2013). El Decreto № 47/03 Programa "Carta compromiso con el Ciudadano", si bien está vigente se discontinuó. 
reingeniería institucional más importante en la historia de la Provincia" (Plan de regionalización... 2010:8).

\subsection{El proyecto de ley Marco para la Regionalización de la Provincia de Buenos Aires}

La provincia está dividida políticamente en 135 partidos o municipios. Pero no es la única división política. Existen 12 regiones sanitarias, 8 secciones electorales, 25 regiones educativas, 7 regiones turísticas, 18 departamentos judiciales (20 creados), 13 corredores productivos además de delegaciones de ARBA, IOMA, IPS, de la Caja de Retiro de Policías, Registro de las Personas, Seguridad Vial, del Ministerio de Trabajo, del Ministerio de Asuntos Agrarios, del Tribunal de Cuentas en diferentes localidades de la provincia.

Es evidente que este esquema de desconcentración administrativa no resulta económico, eficaz, eficiente ni igualitario. Pero como veremos, el actual intento de la gestión bonaerense de Regionalización de la Provincia de Buenos Aires, plan diseñado por el Lic. Santiago Montoya, no ataca estos problemas.

Presentado públicamente en 2010, la actual gestión provincial presentó en marzo de 2011 un proyecto de ley Marco para la Regionalización de la Provincia de Buenos Aires que tiene como objetivo "impulsar su desarrollo institucional, económico y social mediante el despliegue de las capacidades de cada una de las regiones, para disminuir desequilibrios en materia de desarrollo socioeconómico, crecimiento poblacional e infraestructura, mejorando el tejido social con políticas públicas adaptadas regionalmente y para lograr un mayor acercamiento del Estado Provincial a sus habitantes, a través de un proceso de transformación del Estado Provincial profundo y abarcativo" (art. $2^{\circ}$ del proyecto de Ley Marco de Regionalización). ${ }^{33}$

Entre los fundamentos del proyecto se señala la necesidad de realizar una profunda reforma institucional. Se añade que el proyecto supone un nuevo paradigma de Estado; una transformación del Estado Provincial. Allí se indica que la concentración de responsabilidades en la administración central resta eficacia a su accionar ya que la funciones de planificación y

\footnotetext{
${ }^{33}$ www.hcdiputados-ba.gov.ar/proyectos/11-12PE10.doc. Fecha de consulta: 12/11/2013. Entre los fines específicos ese mismo artículo enumera los siguientes: "1. Crear regiones, como instrumento de desconcentración y descentralización de la Administración Central; 2. Fortalecer y ampliar la autonomía municipal, fomentando su asociatividad; 3 Institucionalizar una gestión integrada de la Región Metropolitana; 4. Implantar un modelo de gestión basado en soluciones tecnológicas; 5 . Reestructurar la administración, simplificando trámites y procedimientos."
} 
control han ido cediendo espacio a la resolución de innumerables cuestiones de tipo operativo, que bien podrían ser delegadas en niveles ejecutivos inferiores.

Correctamente se señala que es en el nivel municipal donde se perciben con mayor claridad las necesidades y demandas de los ciudadanos y que por ello es clave la transferencia de funciones y atribuciones a los Municipios. Pero la región es vista como "una instancia de articulación y mediación entre el Estado Provincial y los requerimientos locales" que permita acortar las distancias entre los problemas y las soluciones, sin alterar la unidad política provincial. Más adelante se aclara que la iniciativa está dirigida a generar procesos de desconcentración y descentralización. Agrega que "Desde lo institucional establece expresamente que las actividades de las regiones serán exclusivamente operativas y se dirigen sólo a ejecutar las políticas que defina el gobierno central, en estricto respeto del sistema de distribución de poderes establecido por la Constitución Provincial”. Finalmente, indica que se “define a la región como un ámbito de competencia territorial, asignado a una autoridad provincial ... una jurisdicción presupuestaria autárquica para la administración de los recursos que le asigne anualmente".

Vemos entonces que en los fundamentos aparecen distintos conceptos: transferencia de funciones, articulación y mediación, desconcentración y descentralización, competencia territorial y autarquía.

¿Cuáles son los instrumentos que prevé el proyecto de ley? El artículo $5^{\circ}$ define a la Región como "el ámbito de competencia territorial, asignado a una autoridad provincial con asiento en ella, que tiene a su cargo la ejecución de planes y programas determinados por las políticas provinciales, conforme a las competencias que se establezcan. Cada Región constituye una jurisdicción presupuestaria autárquica para la administración de los recursos que le asigne anualmente la Ley de Presupuesto del Estado Provincial. La Región no constituye una división política distinta de las existentes" 34 .

\footnotetext{
${ }^{34}$ Se define que serán entre ocho (8) y doce (12) más una Región Capital, se integrarán con distritos colindantes y que tendrán no más de un millón cuatrocientos mil (1.400.000) habitantes para el interior y no más de tres millones (3.000.000) para las áreas de coronación de la Ciudad Autónoma de Buenos Aires y además no menos de tres (3) y no más de veinticinco (25) distritos, siendo éstos agrupados en función de la compatibilidad de factores socioeconómicos, históricos y culturales. Además se aclara que se conformará una Región Metropolitana con los Partidos de Almirante Brown, Avellaneda, Berazategui, Escobar, Esteban Echeverría, Ezeiza, Florencio Varela, General San Martín, Hurlingham, Ituzaingó, José C. Paz, La Matanza, Lanús, Lomas de Zamora, Malvinas Argentinas, Merlo, Moreno, Morón, Pilar, Quilmes, San Fernando, San Isidro, San Miguel, Tigre, Tres de Febrero y Vicente López, los que, a su vez, formarán parte de las regiones más pequeñas.
} 
El siguiente artículo define las competencias de la autoridad de aplicación de la ley, todas de índole político y no sustanciales ${ }^{35}$ aunque seguidamente aparece una delegación al Poder Ejecutivo para disponer la adecuación normativa y estructural en las organizaciones territoriales de los Ministerios y Organismos, a propuesta de la Autoridad de Aplicación (artículo $\left.7^{\circ}\right)$.

La otra autoridad prevista en el proyecto es un Consejo Consultivo de la Regionalización de la Provincia integrado por legisladores, representantes del Poder Judicial, representantes de las entidades académicas y representantes de sociedades intermedias relacionadas directamente a la materia; sus funciones, tal como se desprende del nombre del Consejo, son sólo consultivas.

El proyecto de ley marco prevé tres instancias temporales: se determina que la autoridad de aplicación deberá cumplir con una fase de consulta, una fase de formulación con la propuesta de conformación y delimitación territorial de regiones, elaborada a partir de la fase de consulta junto con la propuesta de normativa que resulte necesaria para implementar la regionalización y una fase de implementación para operativizar las propuestas, a través de la elaboración de normas complementarias $y$, en particular, participar en el proceso de formulación del Presupuesto Provincial.

El proyecto Ley no aclara más con lo cual debemos recurrir a otros documentos elaborados por los propiciadores del Plan. En el documento titulado "Plan de Regionalización. Un nuevo paradigma de Estado" del 2011 aparecen más detalles que permiten aclarar las preguntas formuladas.

En el capítulo referido al Diseño Institucional de las Regiones, se señala que "existirán vinculaciones interadministrativas e interogánicas funcionales diferentes de las jerárquicas, se propondrá conformar compromisos de gestión por resultados entre aquellos Ministros y Secretarios encargados de diagramar las políticas provinciales globales y de largo plazo, y aquellos encargados de gestionar diariamente los despachos, expedientes y consultas de la comunidad en relación al Estado" (Plan de Regionalización ..., 2011:31).

\footnotetext{
35 Destacamos las más relevantes: “a) Conducir el proceso técnico político de elaboración de las herramientas normativas que delimiten los ámbitos territoriales de cada Región, en función de objetivos institucionales y de desarrollo económico y social; b) Proponer la delimitación geográfica de las regiones ... ; c) Realizar las reuniones, consultas, audiencias y propuestas ...; d) Convocar a asociaciones y sociedades intermedias interesadas, relacionadas con la regionalización, que puedan realizar aportes para el estudio de la misma; ... h) Realizar reuniones periódicas con los Ministros, Secretarios y Titulares de Organismos y Empresas estatales o públicas a fin de coordinar la implementación de las acciones de descentralización o desconcentración de la administración de acuerdo con el desarrollo del Plan de Regionalización; ...".
} 


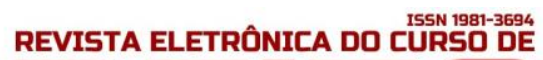

En el documento se propone incorporar dos autoridades con capacidades de decisión diferentes: la encargada de gestionar a nivel regional, a la que se le reconoce la mayor autoridad en el territorio, a veces, llamados ejecutivos regionales y otras administradores regionales (tendrán rango de Subsecretaría) ${ }^{36}$; la otra autoridad, superior a éstos, es quien debe encargarse de su coordinación y que deberá articular con los Ministerios centrales y el Gobernador (que tendrá rango de Ministerio).

Se señala que los ejecutivos regionales tendrán competencia en temas relacionados con educación, salud, infraestructura, medio ambiente, deporte, turismo, obra pública, producción, agricultura y ganadería, entre otros, absorbidas de aquellas con las que actualmente cuentan los Ministerios (Plan de Regionalización ..., 2011:44). Ahora bien, en el esquema propuesto, se adoptará una estructura matricial: las regiones dependerán jerárquicamente del Ministro Coordinador de las Regiones pero funcionalmente de los Ministerios centrales que desconcentren o deleguen en ellas funciones. Y aquí, creemos, se encuentra el talón de Aquiles del proyecto: la relación funcional entre las distintas carteras ministeriales y las Regiones se institucionalizará, señala el documento, a través de Acuerdos o Convenios de Gestión (AG) que incluyan compromisos e incentivos sobre el esquema de gestión basada en resultados. Es decir, las funciones de los ejecutivos regionales dependen de la delegación mediante acuerdos entre los Ministerios centrales y el Ministro Coordinador de las Regiones.

Se señala que estas regiones contarán con un presupuesto protegido (intangible) regional que les deberá ser girado junto con las competencias por los Ministerios centrales con lo cual no se acerca al esquema de autarquía definido en el art. $5^{\circ}$ del proyecto porque estos fondos dependen de este Acuerdo y no vienen asignados por Ley.

El documento que venimos analizando reconoce que la instancia "Técnicamente (es) ... una desconcentración administrativa con “instituciones”, mediante la creación de una nueva estructura orgánica dentro de la Administración Central que, coordinada a través de un Ministerio, asume las competencias de carácter administrativo que cada Ministerio central transpase y las distribuye en las distintas subsecretarías con asiento en cada Región" (Plan de Regionalización ..., 2011:36).

\footnotetext{
${ }^{36}$ Serán representantes del Gobernador en la Región, designados por él. En un documento anterior se decía que en el futuro lo serán por elección indirecta o directa o métodos mixtos. Se señala más adelante que "Las regiones tendrán su propia Dirección General de Administración, que les permita hacer compras y contrataciones, así como su propia Tesorería” (Plan de Regionalización ..., 2011:38).
} 
El proyecto de ley fue aprobado en la Cámara de Diputados de la Provincia en noviembre de 2011 pero, girado recién en 2012 y ser especialmente nombrado en el Discurso de apertura de sesiones de ese año por el Gobernador Scioli, no se aprobó en el Senado. A pesar de diversas reuniones, el titular de ese cuerpo pidió un nuevo debate y desde entonces el proyecto no ha registrado avances. ${ }^{37}$

\subsection{Las líneas ideológicas del proyecto}

El Lic. Montoya sostuvo en su presentación "La realidad provincial cambió, las instituciones deben adaptarse” en el II Seminario internacional de Regionalización que “... la propuesta del Plan de Regionalización no es producir una reforma del Estado. La propuesta es un cambio completo de paradigma, de modelo de Estado. ... (el plan de Regionalización) No es un plan de reforma del Estado, así que no basta con un poco de descentralización y un poco de desconcentración. Se trata de soluciones complejas ...” (Plan de Regionalización ..., 2011:12).

Desde una visión tecnocrática afirma “Las regiones se presentan de este modo como instancias ejecutivas potentes, dinámicas, flexibles, pequeñas. Entendemos que recuperamos la escala administrable del Estado a través de esta propuesta de creación de las regiones. Esto es sentido común, no hay nada que discutir: son 50, 60 o 70 años de consecuencias de otras políticas que trajeron un efecto concentrador en términos de población que nos llevó al hacinamiento" (Plan de Regionalización ..., 2011:13; el destacado me pertenece).

Otro párrafo, que transcribiremos, parece marcar la pauta del la ideología del proyecto cuando dice "El cambio de paradigma de Estado propuesto desde el Plan de Regionalización, requiere de la consideración de las mejores y más eficientes herramientas de gestión empleadas en la Gestión Pública. La búsqueda de mejorar la efectividad de las políticas públicas, la eficiencia en la utilización de los recursos públicos y hacer uso intensivo de las nuevas tecnologías, en pos de brindar servicios públicos con mayor calidad ante una demanda más activa de los ciudadanos, hace que la Administración Pública en general y la de la Provincia en particular, comiencen a dejar el modelo administrativista y burocrático, y adopten modelos que propenden mayor transparencia, mejores y más canales de participación y principalmente más

37 Ver, entre otras noticias, las publicadas en los siguientes sitios: http://www.eldia.com.ar/edis/20120118/mariotto-quieren-nuevo-debate-regionalizacionlaprovincia9.htm; $\quad$ http://www.infoplatense.com.ar/index.php/provincia/5656-mariotto-y-montoyajuntos-por-regionalizacion. Fecha de acceso: 29/09/2014. 
dinámicos y flexibles" (Plan de Regionalización ..., 2011: 31). Esto es, más eficiencia de las herramientas; más efectividad de las políticas públicas; un modelo administrativo y burocrático rígido que debe abandonarse (¿por otro?) por no ser transparente ni participativo ni flexible.

La adscripción ideológica del modelo estatal es explícita: la nueva gestión pública y a renglón seguido se confirma cuando propone “... la adopción de sistemas de gestión orientados a resultados, estructuras matriciales, relaciones funcionales y jerárquicas, planeamiento estratégico, etc., son medios y/o herramientas que permiten potenciar la gestión del Estado en el territorio y de las unidades regionales con el Estado Central" (Plan de Regionalización ..., 2011:31). Luego define, en esta lógica, a "Las Regiones, como unidades administrativas innovadoras, se gestan como áreas del Estado altamente ejecutivas, dinámicas y flexibles" (Plan de Regionalización ..., 2011:33).

Más adelante volvemos a encontrar esta fundamentación y adscripción ideológica: “ ... el actual esquema propone reemplazar el modelo tradicional de organización y entrega de servicios públicos, basado en los principios de la jerarquía burocrática, la centralización y el control directo, por una nueva gerencia pública que fortalezca la eficiencia y eficacia. En otras palabras, promueve ir de la administración pública a la gerencia pública ... La razón principal de la creación de una nueva estructura de administradores regionales es la de separar las funciones ejecutivas de la formulación de políticas, ahora en mano de los Ministerios sectoriales, estos últimos con sede en la capital de la Provincia. Dicha separación permitirá introducir ciertos principios de la gerencia privada en la administración pública, monitoreando un compromiso de gestión. Claro está que para ello es necesario dotar de responsabilidades a los Administradores Regionales a efectos de poder ejecutar las políticas públicas diseñadas a nivel central" (Plan de Regionalización ..., 2011:40).

\section{CONCLUSIÓN}

Resulta evidente, tanto por su expresa mención, por los criterios de valoración como por los instrumentos que utiliza, que el Plan de Regionalización para provincia de Buenos Aires adscribe a los postulados de la nueva gestión pública. La gestión por resultados, las estructuras matriciales, la mixtura de relaciones funcionales y jerárquicas, las unidades administrativas dinámicas y flexibles junto con los criterios de eficiencia y eficacia son elementos claros que intentan romper con la actual estructura administrativa. 


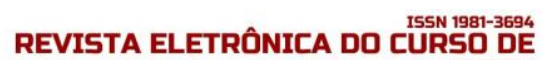

Sin embargo, cuando se analizan las herramientas para ello, la clave de bóveda del sistema son los Acuerdos Gubernamentales. Esta idea de “delegación” de funciones a través de acuerdos entre los Ministerios Centrales con las regiones, constituye, como decíamos más arriba, en el aspecto político, jurídico y administrativo crítico: político, porque no habrá incentivos en "delegar" en los ejecutivos regionales si la responsabilidad política sigue siendo de los Ministerios Centrales; jurídica, porque no quedan claras las responsabilidades de la falta de cumplimiento de estos AG por cualquiera de las dos partes y administrativa, justamente, porque introduce la figura de "partes" y competencia dentro de la administración pública incentivando, además, la obtención de resultados para obtener presupuesto, crítica ya no propia del proyecto en sí sino de la lógica de la Nueva Gestión Pública a la que adscribe el plan.

No está de más recordar para el lector el desprestigio que las políticas de la Nueva Gestión Pública han tenido en Argentina, en general y en la Provincia en particular, como consecuencia de haber estado asociadas a las reformas de primer generación que minaron el Estado nacional argentino mediante un complejo proceso que no sólo implicó privatizaciones, jubilaciones anticipadas, transferencias de competencias a las provincias sino y muy especialmente un desprestigio hacia lo público que aún hoy resulta muy difícil de revertir.

Esta "estrategia de reingeniería institucional" para un "Un nuevo paradigma de Estado" termina en una mera desconcentración administrativa en otros órganos administrativos, ciertamente más cerca del territorio pero sin competencia propia (sino dependiente de acuerdos) y sin presupuesto propio (dependiente de la transferencia de los recursos de los ministerios centrales a las regiones). En este sentido, el plan no parece ser innovador respecto del proceso de regionalización interprovincial. Muchas veces se aclara que no se crea sino un ámbito de competencia territorial pero sin competencias propias; los ejecutivos o administradores regionales no son sino funcionarios que dependen de las competencias que se les deleguen; sin esa delegación, parece un eslabón burocrático más que hace que la ciudad de La Plata esté más lejos y no más cerca. Sin una competencia propia (sea en función de algunas materias, de los montos, de las distancias) no hay funciones que cumplir. En este sentido, la desconcentración por acuerdos no parece ser la mejor solución.

Nada se dice acerca de la ventanilla única aunque esa parece ser la lógica del proyecto. Es verdad que se trata de un proyecto de ley marco pero ¿es dable suponer que los Ministerios, Organismos de la Constitución y organismos autárquicos cierren sus oficinas para que otro Ministerio asuma sus funciones? No, bajo las actuales formas de pensar la Administración. 
Integrarse es una estrategia política de largo plazo que necesariamente tiene sus tiempos de maduración y estudio de alternativas pero también requiere de ambición. Los magros resultados de los actuales procesos provinciales de regionalización son una muestra de ello. Los diseños de escritorio no son una opción.

\section{REFERENCIAS}

Aguilar Villanueva, L. (2006). Gobernanza y gestión pública. México: Fondo de Cultura Económica.

Badeni, G. (1994). Reforma constitucional e instituciones políticas. Buenos Aires: Ad-Hoc.

Barrera Buteler, G. (1996). Provincias y Nación. Buenos Aires: Ediciones Ciudad Argentina.

Bianchi, A. B. y Seville Salas, V. (1996). La región patagónica. Una primera concreción del regionalismo. Revista La Ley 1996-E, p.1381.

Bidart Campos, G. J. (1995). Tratado elemental de derecho constitucional argentino, tomo VI "La reforma constitucional de 1994", Buenos Aires: Ediar.

Buenos Aires (2010). Plan de regionalización. Un estado inteligente para la provincia del futuro. La Plata: Ed. Plan de Regionalización de la provincia de Buenos Aires.

Buenos Aires (2011). Plan de Regionalización de la provincia de Buenos Aires. Un nuevo paradigma de Estado. La Plata: Ed. Plan de Regionalización de la provincia de Buenos Aires.

Camou, A., dir. (2005). Estudio de permeabilidad de las estructuras organizativas del Estado provincial respecto de las políticas sociales y del control de los recursos económicos. Programa de Subsidios para Proyectos de Investigación y Desarrollo y Transferencia con Organismos Públicos de la Provincia de Buenos Aires. Instituto Provincial de la Administración Pública y Departamento de Sociología de la Universidad Nacional de La Plata.

CEPAL (1994). El regionalismo abierto en América Latina y el Caribe. Santiago de Chile: Naciones Unidas.

CHERESKY, I. Comp. (2006). La política después de los partidos. Buenos Aires: Prometeo.

Dalla Vía, A. R. (2000).Actualidad del federalismo argentino. Revista La Ley NOA, pp. 447 Domingo, H. L. y Moscariello, A. R. (2007). Personalidad jurídica de la región centro. Revista La Ley Litoral 2007 (noviembre), p 1027.

Ferrando Badía, F. (1976). Estudios de Ciencia Política. Madrid: Tecnos. 


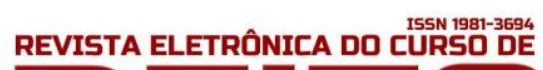

González, J. V. (1913). Diario de sesiones de la Cámara de Senadores. Volumen 2. Buenos Aires: El comercio. Discurso del 23/08/1913.

Gordillo, A. (1998). La Región Argentina a partir de la constitución de 1994. Después de la reforma del Estado. Buenos Aires: Fundación de Derecho Administrativo.

Haas, E. B. (1966). Partidos políticos y grupos de presión en la integración europea. Revista INTAL-BID, Buenos Aires, p. 17.

Hernandez, A. M. (1997). Federalismo, Autonomía Municipal y Ciudad de Buenos Aires en la reforma constitucional de 1994. Buenos Aires: Depalma.

Klass, R. J. (2004). La relación entre Nación y Provincias: En busca de un delicado equilibrio. Revista LA LEY 2004-A, pp. 1421.

Mellado, N. B. (2005). Integración regional. Insuficiencias de las perspectivas teóricas. Revista Anales UNLP-2005, Tomo 36, 385.

Ollier, M. M. (2011). Atrapada sin salida. Buenos Aires en la política nacional (1916-2007). Buenos Aires: UMSAN Edita.

Pagani, M. L., Quintans, N., Migliore, A., y García M.E. (2012). Modernización en la provincia de Buenos Aires: presentación de casos. VII Jornadas de Sociología de la UNLP. "Argentina en el escenario latinoamericano actual: debates desde las ciencias sociales organizado por el Departamento de Sociología de la Facultad de Humanidades y Ciencias de la Educación (UNLP) realizadas los días 5, 6 y 7 de diciembre 2012. Publicado en las Actas de las Jornadas en jornadassociologia.fahce.unlp.edu.ar/actas/Pagani.pdf/at_download/file

Piaggi, A. I. (1999). Integración, regionalización: idea y realidad. Revista La Ley 1999-C , p. 1037.

Piana, R. S. (2009). ¿UNASUR u otro intento fallido? Sobre las políticas de (no) integración en Sudamérica. Rivisita Studi sull integrazione europea $n^{\circ} 2$ - 2009 Año IV. Bari, Italia.

Piana, R. S. (2012 b). La reforma de la Administración Pública en la Provincia de Buenos Aires. Su estudio en los años de la gestión 2002-2007. Ricardo Sebastián Piana (Ed.), E-book. ISBN 978987-45238-0-8. Disponible en: http://hdl.handle.net/10915/31545

Piana, R. S. (2012). El Estado. Un recorrido teórico por los temas de hoy. La Plata: EDULP.

Piana, R.S., y Baeza, N. (2013). “Candidatos a medida- ¿Cómo se construyó el candidato que le ganó a los Kirchner?" en Revista de la Facultad de Derecho y Ciencias Políticas de la Pontifica Universidad Bolivariana, Vol 44, No 119 (2013), Medillín. Disponible en http://revistas.upb.edu.co/index.php/derecho/index. ISSN: 0120-3886.

Portinaro, P. P. (2003). Estado. Léxico de política. Buenos Aires: Nueva Visión.

Quiroga Lavie, H. (1996). Constitución de la Nación Argentina Comentada. Buenos Aires: Ed. Zavalía. 
Rodríguez, D. y Rodríguez Blanco, M. (2004) ¿Lealtad peronista o desafección partidaria?. Las elecciones de 2003 en la provincia de Buenos Aires. Cheresky, I. y Pousadela, I. (comp.), El voto liberado: elecciones 2003: perspectiva histórica y estudio de casos. Buenos Aires: Biblios.

Rosatti, H. (1994). El federalismo en la reforma. La Reforma de la Constitución explicada por miembros de la Comisión de Redacción. Santa Fe: Rubinzal Culzoni.

Sabsay, Daniel Alberto (2013). El federalismo y la incorporación de la noción de región en la reforma constitucional de 1994. Revista La Ley 2013-C, p. 1172. 